\title{
HEMOSTATIC EFFICACY OF TOPICAL APPLICATION OF INJECTABLE FORM OF TRANEXAMIC ACID IN ENDOSCOPIC PARTIAL INFERIOR TURBINECTOMY
}

\author{
By \\ Osama Mohamed Refaat \\ Otorhinolaryngology Department, Faculty of Medicine, Al-Azhar University, Cairo \\ E-mail: osamarefaat78@gmail.com
}

\begin{abstract}
Background: Nasal obstruction due to hypertrophied inferior turbinates (HIT) is one of the common reasons of patients' attending Otolaryngology clinics. Endoscopic partial inferior turbinectomy associated with intraoperative nasal bleeding which can obscure the visibility of the field and prolong time of surgery. Tranexamic acid (TXA) acts as a competitive antagonist at the lysine site on plasminogen. So, it acts as an anti-fibrinolytic agent by inhibiting the tissue plasminogen activator, and with this mechanism in the coagulation cascade, it can be applied topically to decrease intra-operative bleeding.
\end{abstract}

Objective: To evaluate hemostatic effect of topical application of TXA on the surgical field after endoscopic partial inferior turbinectomy.

Patients and Methods: A prospective randomized clinical study included 50 patients with chronic nasal obstruction due to bilateral HIT, attending the ENT outpatient clinics of Al-Azhar University Hospitals between Jan 2015 and May 2016. They were randomly allocated into two equal groups: Study group underwent endoscopic partial turbinectomy with TXA, and control group underwent endoscopic partial turbinectomy with normal saline alone. Patients were seen 1, 3, 4 weeks post-operatively.

Results: In the study group, $60 \%$ were males and $40 \%$ were females and in control group $68 \%$ were males and $32 \%$ were female, with an average age of $32.1 \pm 5$ years in the study group and $31.9 \pm 7.3$ years in the control group. The average bleeding score was $2.2 \pm 0.6$ in the study group, while it was $2.6 \pm 0.7$ in the control group. The mean bleeding time was $7 \pm 2.5 \mathrm{~min}$. in study group, while the control group was $12 \pm 4.8$ min. The mean blood volume lost in the study group was $51 \pm 14.1 \mathrm{ml}$, while $75 \pm 14.2 \mathrm{ml}$ in the control group.

Conclusion: Using of tranexamic acid during endoscopic partial turbinectomy minimized intraoperative bleeding and improved surgical field and less time consuming.

Key Words: Hypertrophied inferior turbinate, nasal obstruction, hemostasis, tranexamic acid, partial inferior turbinectomy.

\section{INTRODUCTION}

The inferior nasal turbinate is a vital structure which has an important role in nasal physiology, including warming, filtration, humidification and regulation of nasal airflow. However nasal inferior turbinate (IT) enlargement either due to hypertrophy or oedema decreases nasal airflow with feeling of nasal blockage. Persistent nasal obstruction can affect quality of life, so many medical trials exist to resolve secondary nasal obstruction to enlarged inferior nasal turbinates; however, surgical management is often 
recommended when these medical therapies fail (Scheithauer, 2010). HIT composed of thickened bone core covered medially by hypertrophied nasal mucosa containing numerous seromucinous glands and engorged venous blood sinusoids which increased significantly in hypertrophic mucosa of IT (Hegazy et al., 2014), so HIT has a rich and variable blood supply, mainly supplied by the posteriorly located IT branch originating from the sphenopalatine artery (Orhan et al., 2010). HIT graded into: Grade I which is a normal sized; Grade II moderate size filling half of the nasal cavity but didn't touch nasal septum and Grade III huge size filling whole nasal cavity and touching nasal septum (Macario et al., 2015).

Different maneuvers have been described for reduction of HIT which not responding for medication included; total, partial or submucous turbinectomies, turbinoplasties, electrocautery, chemocautery, cryosurgery, laser surface surgery, endoscopic shaver turbinectomy and coblation. These surgical techniques differ in the amount and type of tissue resection and preservation which aim to achieve both maximal symptom improvement and preservation of function (Cingi et al., 2010). Endoscopic inferior partial turbinectomy is one of the most commonly performed nasal surgical procedures to relieve nasal obstruction due to IT enlargement (Cheng et al., 2012).

Trans and post-operative nasal bleeding consider one of the common complications of surgical turbinectomy (Kassim, 2011), leading to difficulty in recognizing important nasal surgical landmarks and structures, so it increases the rate of intra-operative hazards, prolong the operating time and result in incomplete surgery, so visibility of the surgical field is mandatory for safety of the operation (Timperley et al., 2010). Surgical field can be estimated by Boezaart grading as follow: $0=$ no bleeding. 1 = slight bleeding, no suction required. $2=$ slight bleeding, occasional suctioning required, surgical field not threatened. 3 = slight bleeding, frequent suctioning required, bleeding attacks surgical field a few seconds after removal of suction. $4=$ moderate bleeding, frequent suctioning required, bleeding obscure surgical field directly after suction is removed. 5 = severe bleeding, continues suctioning required, bleeding appears faster than can be removed by suction, surgical field severely threatened.

Tranexamic acid (TXA) (trans-4 amino methyl-cyclohexane carboxylic acid) is a synthetic lysine derivative act as a competitive antagonist at the lysine site on plasminogen (Ligon and Almazani, 2016). Activation of fibrinolysis during and after surgical procedure is a well-known Phenomenon. The tissue plasminogen activator is released due to tissue damage during surgery, which can convert tissue plasminogen to plasmin, promote fibrinolysis and activate the fibrinolytic system. Thus, TXA acts as an antifibrinolytic agent by inhibiting the tissue plasminogen activator (Jabalameli and Zakeri, 2014). There is strong evidence that TXA reduces blood loss in surgery. So, it can be applied either locally or systemically with this mode of action in the coagulation cascade to minimize intraoperative bleeding (Jahanshahi et al., 2014). Systemic infusion of TXA 
associated with several adverse effects such as nausea, vomiting, diarrhea, allergic dermatitis, dizziness, hypotension, seizures, impaired vision and particularly thromboembolic events (Ker et al., 2012).

The present work aimed to evaluate hemostatic effect of topical application of TXA on the surgical field after endoscopic partial inferior turbinectomy.

\section{PATIENTS AND METHODS}

This prospective randomized study was performed on 50 patients presented by resistant nasal obstruction due to chronic hypertrophic rhinitis with bilateral HIT for more than 3 months not responding to medical treatment. Patients attended ENT outpatient clinics of Al-Azhar University Hospitals during the period between Jan 2015 and May 2016. This study was approved by the local Ethics and Research Committee of Faculty of Medicine, AlAzhar University. A written consent was obtained from all patients after full explanation of the study. All patients in this study underwent bilateral endoscopic partial inferior turbinectomy by the same surgeon. Patients were randomly divided into two equal groups: Study group those patients subjected for topical application of TXA for hemostasis, and control group for those normal saline was used.

Full history taken included general and ENT history with a special attention to onset, course (intermittent or continuous), duration of nasal obstruction, site (unilateral or bilateral), associated nasal discharge and previous used nasal medication (decongestant, corticosteroid, and anti-histamine). Full nasal examinations and tests included anterior rhinoscopy, endoscopic nasal and nasopharynx examination $\left(2.7 \mathrm{~mm} 0^{\circ}\right)$ to confirm diagnosis and exclude posterior nasal pathology, cold spatula test, cotton wisp test, Cottles maneuver. Radiological assessment: axial and coronal computed tomography (CT) for nose and para-nasal sinuses to confirm diagnosis and also exclude any associated sinus pathology. Laboratory investigations included CBC, FBS, prothrombin time (PT), Partial thromboplastin time (PTT), international normalized ratio (INR), clotting time, bleeding time, liver and kidney functions. Inclusion criteria: Patients with chronic nasal obstruction for more than 3 months due to isolated bilateral HIT (grade II \& III), not improved with medication (decongestant, corticosteroids or antihistamine), Hemoglobin not less than 10 $\mathrm{mg} / \mathrm{dl}$, normal coagulation profile. Exclusion criteria: other associated causes for nasal obstruction (deviated nasal septum, sinusitis with or without nasal polyposis), previous nasal surgery, patients with uncontrolled hypertension, anti-coagulant therapy, any blood diseases.

Patients were pre operatively prepared with bilateral decongestant nasal pack for 15 minutes. Unger general anesthesia patients placed on $30^{\circ}$ position and their mean arterial blood pressure kept $60-70$ $\mathrm{mmHg}$. By using $2.7 \mathrm{~mm}, 0$ degree rigid nasal endoscopy bilateral partial inferior turbinectomy had done. In study group: Hemostasis done by using cotton pledgets soaked with TXA solution (1000 mg diluted in $20 \mathrm{ml}$ normal saline), while in control group: Cotton pledgets soaked with normal saline were used. All patients assessed intra-operative for time need for hemostasis, surgical field by using Boezaart grading and post-operative for 
total blood loss in suction bottle after extraction volume of irrigating normal saline, total operative time and complications (nausea, vomiting and rebleeding within the next $48 \mathrm{~h}, 1,3,4$ weeks). $\mathrm{P}$ value less than 0.05 was consider statistically significant.

\section{Statistical Analysis:}

Numerical data were explored for normality by checking the distribution of data and using tests of normality (Kolmogorov-Smirnov and Shapiro-Wilk tests). Age, blood loss and total OR time data showed normal (parametric) distribution while bleeding score and time needed for hemostasis data showed non- parametric distribution. Data were presented as mean, standard deviation (SD), 95\% Confidence Interval (95\% CI), median and range values. For parametric data, Student's t-test was used to compare between the two groups. For nonparametric data, Mann-Whitney $U$ test was used to compare between the two groups. Qualitative data were presented as frequencies and percentages. Chi-square test or Fisher's Exact test when applicable were used to compare between qualitative data in the two groups. Statistical analysis was performed with IBM SPSS Statistics for Windows, Version 23.0. Armonk, NY: IBM Corp.

\section{RESULTS}

Total 50 patients, study group 15 $(60 \%)$ were males and $10(40 \%)$ were females, while control group $17(68 \%)$ were males and $8(32 \%)$ were females, with a mean age of $32.1 \pm 5$ years in study group, and $31.9 \pm 7.3$ years in the control group underwent analysis. There was no statistically significant difference between gender distributions and mean age values in the two groups. Turbinate size grades II, III in study group were $9(36 \%), 16$ $(64 \%)$ respectively, while in control group it were $11(44 \%), 14(56 \%)$ respectively. There was no statistically significant difference between turbinate sizes in the two groups (Table 1).

Table (1): Mean, standard deviation (SD), frequencies (n), percentages (\%) and results of Student's t-test and Chi-square test for comparisons of parameters in the two groups

\begin{tabular}{|c|c|c|c|}
\hline $\begin{array}{ll}\text { Parameters } & \text { Groups } \\
\end{array}$ & $\begin{array}{c}\text { Control group } \\
(\mathbf{n}=25)\end{array}$ & $\begin{array}{c}\text { Study group } \\
(\mathbf{n}=25)\end{array}$ & $P$-value \\
\hline $\begin{array}{l}\text { Age (year) } \\
\text { Mean (SD) }\end{array}$ & $31.9 \pm 7.3$ & $32.1 \pm 5$ & 0.911 \\
\hline \multicolumn{4}{|l|}{ Gender [n (\%)] } \\
\hline Male & $17(68 \%)$ & $15(60 \%)$ & \multirow{2}{*}{0.556} \\
\hline Female & $8(32 \%)$ & $10(40 \%)$ & \\
\hline \multicolumn{4}{|l|}{ Turbinate size [n (\%)] } \\
\hline Grade II & $11(44 \%)$ & $9(36 \%)$ & \multirow{2}{*}{0.564} \\
\hline Grade III & $14(56 \%)$ & $16(64 \%)$ & \\
\hline
\end{tabular}


Intra- operatively mean bleeding score in study group was $2.2 \pm 0.6$ while it was $2.6 \pm 0.7$ in control group. Study group showed statistically significantly lower median bleeding score than control group. Regarding to hemostasis time, study group showed $7 \pm 2.5$ min while control group was $12 \pm 4.8 \mathrm{~min}$. Study group showed statistically significantly lower median time needed for hemostasis than Control group. Post- operatively mean total blood loss in study group was $51 \pm 14.1 \mathrm{ml}$ while it was $75 \pm 14.2 \mathrm{ml}$ in control group. Study group showed statistically significantly lower mean blood loss than Control group. Regarding to total OR time in study group was $18.5 \pm 3.8$ min while it was $26 \pm 3.8 \mathrm{~min}$ in control group. Study group also showed statistically significantly lower mean total OR time than Control group (Table 2).

Table (2): Descriptive statistics and results of Mann-Whitney U test and Student's ttest for comparison between intra and post-operative assessment criteria in the two groups

\begin{tabular}{|c|c|c|c|c|c|c|}
\hline$\overbrace{\text { Assessment }}^{\text {Groups }}$ & $\begin{array}{r}\text { Contrc } \\
(\mathrm{n}=\end{array}$ & $\begin{array}{l}\text { group } \\
\text { 5) }\end{array}$ & $\begin{array}{l}\text { Study } \\
\quad(\mathbf{n}=\end{array}$ & $\begin{array}{l}\text { roup } \\
\text { 5) }\end{array}$ & $\begin{array}{c}\text { P- } \\
\text { value }\end{array}$ & $\begin{array}{c}\text { Effect } \\
\text { size } \\
\text { (d) }\end{array}$ \\
\hline Intra- operative & $\begin{array}{l}\text { Median } \\
\text { (Range) }\end{array}$ & $\begin{array}{l}\text { Mean } \\
\text { (SD) }\end{array}$ & $\begin{array}{l}\text { Median } \\
\text { (Range) }\end{array}$ & $\begin{array}{l}\text { Mean } \\
\text { (SD) }\end{array}$ & & \\
\hline Bleeding score & $3(2-4)$ & $2.6 \pm 0.7$ & $2(1-4)$ & $2.2 \pm 0.6$ & 0.012 & 0.614 \\
\hline $\begin{array}{l}\text { Time needed for } \\
\text { hemostasis (Min) }\end{array}$ & $10(5-20)$ & $12 \pm 4.8$ & $5(5-10)$ & $7 \pm 2.5$ & $<0.001$ & 1.306 \\
\hline Post- operative & Mean (SD) & 95\% CI & Mean (SD) & 95\% CI & & \\
\hline Total blood loss (ml) & $75 \pm 14.2$ & $69.1-80.9$ & $51 \pm 14.1$ & $45.2-56.8$ & $<0.001$ & 1.696 \\
\hline Total OR time (Min) & $26 \pm 3.8$ & $24.4-27.6$ & $18.5 \pm 3.8$ & $16.9-20.1$ & $<0.001$ & 1.948 \\
\hline
\end{tabular}

There was no statistically significant difference between prevalence of post- operative complications in the two groups (Table 3).

Table (3): Frequencies (n), percentages (\%) and results of Fisher's Exact test for comparison between prevalence of rebleeding in the two groups

\begin{tabular}{|c|c|c|c|c|c|c|}
\hline \multirow{2}{*}{ Rebleeding Groups } & \multicolumn{2}{|c|}{$\begin{array}{l}\text { Control } \\
\text { group } \\
(\mathbf{n}=25)\end{array}$} & \multicolumn{2}{|c|}{$\begin{array}{l}\text { Study group } \\
\quad(\mathbf{n}=\mathbf{2 5})\end{array}$} & \multirow[t]{2}{*}{$P$-value } & \multirow[t]{2}{*}{$\begin{array}{c}\text { Effect size } \\
\text { (v) }\end{array}$} \\
\hline & $\mathbf{N}$ & $\%$ & $\mathbf{N}$ & $\%$ & & \\
\hline No & 18 & 72 & 22 & 88 & \multirow{4}{*}{0.457} & \multirow{4}{*}{0.228} \\
\hline After 2 days & 3 & 12 & 2 & 8 & & \\
\hline After 5 days & 3 & 12 & 1 & 4 & & \\
\hline After 7 days & 1 & 4 & 0 & 0 & & \\
\hline
\end{tabular}




\section{DISCUSSION}

For proper reduction of HIT with maintenance the functional performance of the remaining portion, this can be achieved by gathering between using endoscopic nasal surgery which make the procedure more precise and perfect and good visualization of the surgical field which can be achieved by making the surgical field bloodless as much as possible. So endoscopic inferior partial turbinectomy consider one of the most common procedures used for reduction HIT which has the advantage of less cost, effective and has good outcome (Rai et al., 2013).

Intra and post-operative bleeding one of the main complication of partial turbinectomy and submucosal resection techniques which represent about $10 \%$ and 5\%, respectively which in turn interfere with the exposure of the field and eventually affect the outcome of the surgery (Ragab and Hassanin, 2010).

General anesthesia cause increasing intra-operative bleeding during surgery through lowering capillary resistance, which in turn leads to difficulty in identifying important anatomic landmarks and structures, and can increase the risk of intra-operative complications, prolong the operating time, and result in incomplete surgery, so many attempts have been achieved to minimize intra-operative bleeding during endoscopic nasal surgery as, bipolar diathermy, nasal packing, local vasoconstrictors, and hypotensive technique, but each one has its adverse effect; diathermy can cause mucosal destruction with delayed bleeding and crustation, topical vasoconstrictors lead to hemodynamic instability especially in those with a history of hypertension or ischemic heart disease (Hathorn et al., 2013).

Kim et al. (2019) reported in their study that systemic application of TXA minimize blood loss during surgical operation which in turn decrease operative time, but Herron et al. (2018) reported that, it has high incidence of postoperative sequels as dizziness, nausea, headache and vomiting after nasal surgery which reported to be $34 \%$ to $65 \%$. Mc Cormack (2012) reported that topical application of TXA may be safer than intravenous administration as its plasma concentration markedly reduced compared to intravenous. Regarding to efficacy of topical application of TXA on reduction of both blood loss and time consumption during nasal surgery Montroy et al. (2018) reported that local using of TXA during surgery is highly effective in reducing intra- operative blood loss and subsequent rate of blood transfusions. Jahanshahi et al. (2014) mentioned in their studies, that topical application of TXA can efficiently reduce bleeding and improve the surgical field in FESS in patients with rhinosinusitis. Ahmed et al. (2014) reported in their study conducted on 75 patients scheduled for FESS under general anesthesia that using of local TXA and local hot saline up to $50^{\circ} \mathrm{C}$ achieved decreasing in blood loss, minimize duration of surgery and improved quality of surgical field.

\section{CONCLUSION}

Topical application of tranexamic acid during endoscopic partial turbinectomy minimizes intraoperative bleeding and improves surgical field and less time consuming. 


\section{REFERENCES}

1. Ahmed S, Mohammed $S$ and Mohammed H (2014): Topical tranexamic acid versus hot saline for field quality during endoscopic sinus surgery The Egyptian Journal of Otolaryngology, 30:327-331.

2. Cheng P, Fang $K$ and Su H (2012): Improved objective outcomes and quality of life after adenotonsillectomy with inferior turbinate reduction in pediatric obstructive sleep apnea with inferior turbinate hypertrophy. Laryngoscope, 122(12):2850-2854.

3. Cingi C, Ure B and Cakli H (2010): Microdebrider-assisted versus radiofrequency-assisted inferior turbinoplasty: a prospective study with objective and subjective outcome measures. Acta. Otorhinolaryngol Ital., 30:138-143.

4. Hathorn I, Habib A and Manji J (2013): Comparing the reverse Trendelenburg and horizontal position for endoscopic sinus surgery: a randomized controlled trial. Otolaryngology - Head and Neck Surgery, 148:608-13.

5. Hegazy M, Mohamed A and ElHennawy A (2014): Histopathological study of hypertrophic inferior turbinate. Egypt J Otolaryngology, 30:23-9.

6. Herron $\mathbf{J}$, French $\mathbf{R}$ and Gilliam $A$ (2018): Civilian and military doctors' knowledge of tranexamic acid (TXA) use in major trauma: a comparison study. J R Army Med Corps; 164:170-1.
7. Jabalameli M and Zakeri K (2014): Evaluation of topical tranexamic acid on intra-operative bleeding in endoscopic sinus surgery. Iran J. Med. Sci., 31:221- 3.

8. Jahanshahi J, Hashemian $F$ and Pazira S (2014): Effect of topical tranexamic acid on bleeding and quality of surgical field during functional endoscopic sinus surgery in patients with chronic rhinosinusitis: a triple blind randomized clinical trial. PLo. S. One, 9:e104477.

9. Kassim R (2011): Prevalence of early complications of partial inferior turbinectomy. Kufa Med. Journal, 14(1): 231- 235.

10. Ker K, Edwards $P$ and Perel $P$ (2012): Effect of tranexamic acid on surgical bleeding: systematic review and cumulative meta-analysis. BMJ, 344:e3054.

11. Kim D, Kim $S$ and Kang $H$ (2019): Efficacy of Tranexamic Acid on Operative Bleeding in Endoscopic Sinus Surgery: A Meta-analysis and Systematic Review, Laryngoscope, 129:800-807.

12. Ligon J and Almazani N (2016): The effectiveness of intravenous tranexamic acid on blood Loss and surgical time during endoscopic sinus surgery: a systematic review. Anaesthesist, 31:8-12.

13. Macario $C$, Soroush $Z$ and Victor $C$ (2015): Inferior turbinate classification system, grades 1 to 4 : development and validation study Laryngoscope, 125(2):296-302. 
14. McCormack $P$ (2012): Tranexamic acid: a review of its use in the treatment of hyperfibrinolysis. Drugs, 72:585-617.

15. Montroy $J$, Hutton $B$ and Moodley $P$ (2018): The efficacy and safety of topical tranexamic acid: A systematic review and meta-analysis Transfusion Medicine Reviews, 32(3):165-178.

16. Orhan M, Midilli $\mathbf{R}$ and Gode $\mathbf{S}$ (2010): Blood supply of the inferior turbinate and its clinical applications. Clin. Anat., 23(7):770-776.

17. Ragab $S$ and Hassanin $M$ (2010): Optimizing the surgical field in pediatric functional endoscopic sinus surgery: a new evidence-based approach. Otolaryngol Head Neck Surg., 142:48-54.
18. Rai S., Sharma $V$ and, Koirala $K$ (2013): Endoscopic versus conventional method for partial inferior turbinectomy in chronic hypertrophic rhinitis. Nepal Journal of Medical Sciences, 2(2):102-7.

19. Scheithauer $M$ (2010): Surgery of the turbinates and "empty nose" syndrome. GMS Curr. Top Otorhinolaryngol. Head Neck Surg., 9: Doc 03. ISSN: 1865-1011.

20. Timperley D, Sacks $\mathbf{R}$ and Parkinson R (2010): Perioperative and intraoperative maneuvers to optimize surgical outcome in skull base surgery. Otolaryngologic. Clinics of North America, 43:599730. 


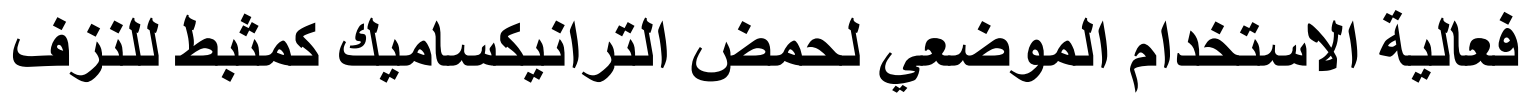

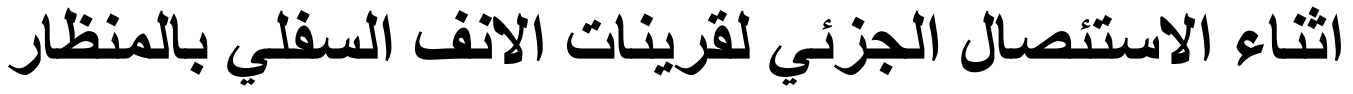 أسامة محمد رفعت
}

\author{
قسم الأنف والأنن والحنجرة، كلية الطب، جامعة الأزهر، القاهرة
}

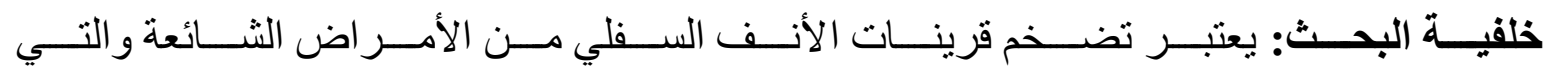

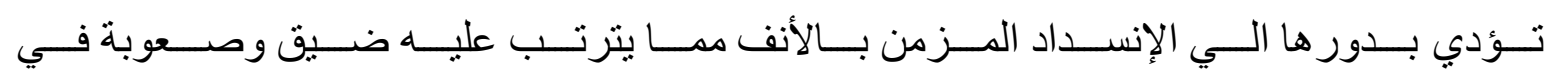

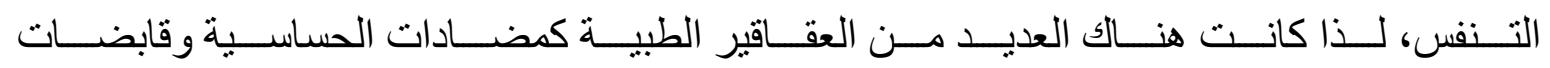

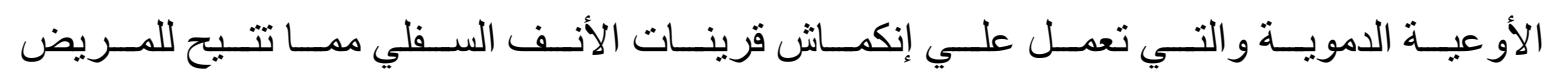

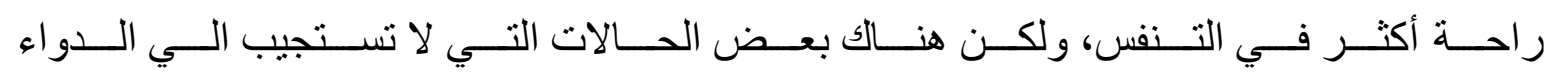

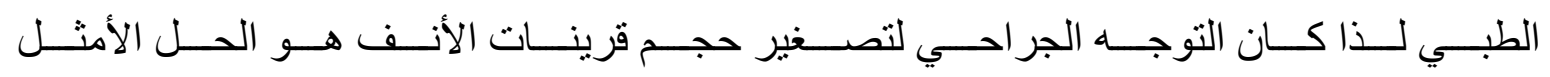

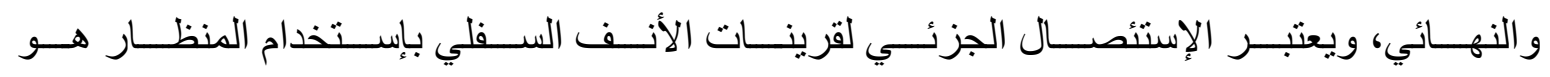

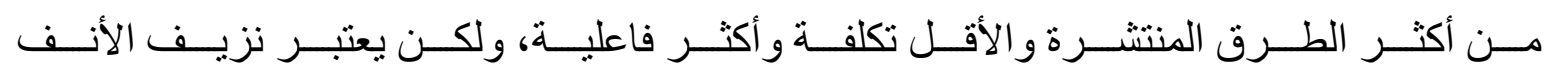

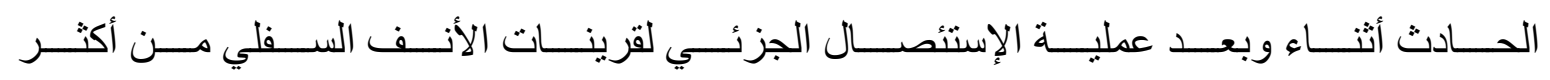

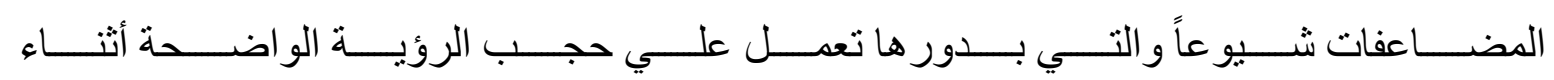

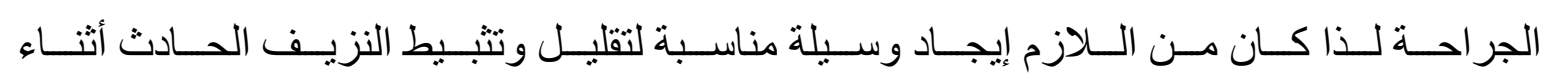
وبعد العملية.

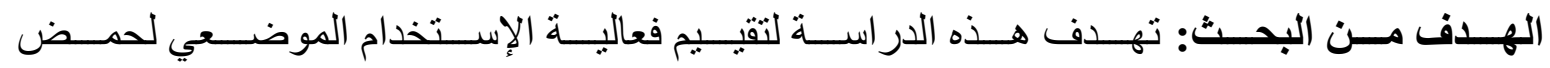

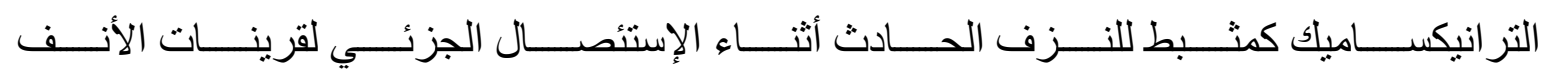
السفلي بالمنظار .

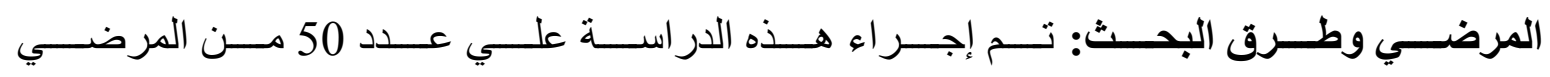

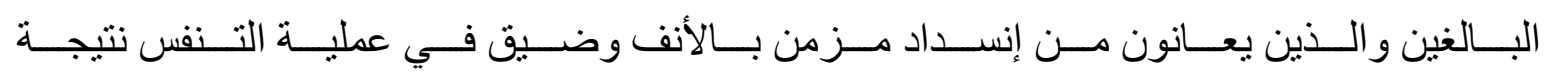

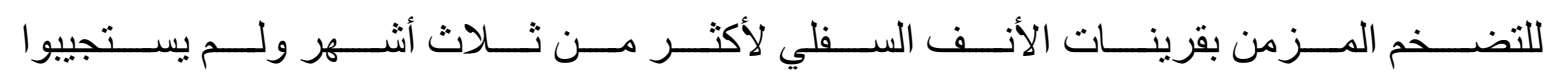

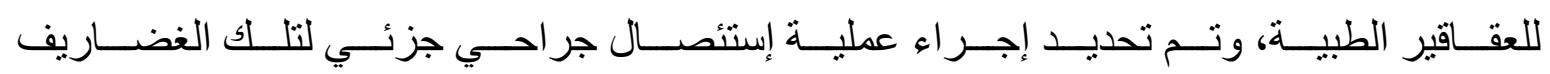

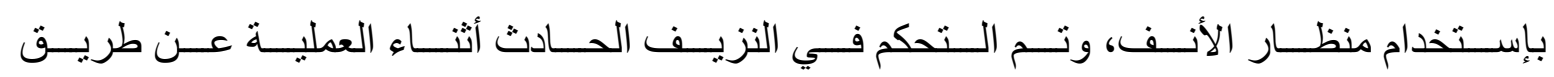

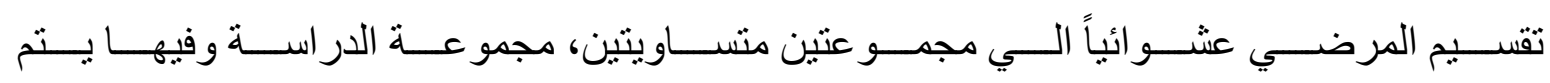

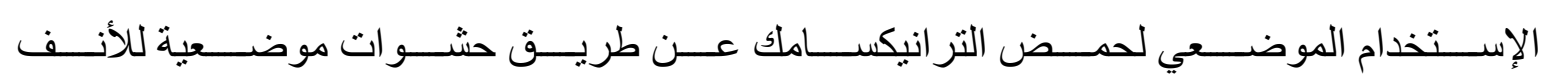
ومجمو عة التحكم وفيها يتم إستخدام حشو ات أنفية مبلله بمحلول ملحي. 


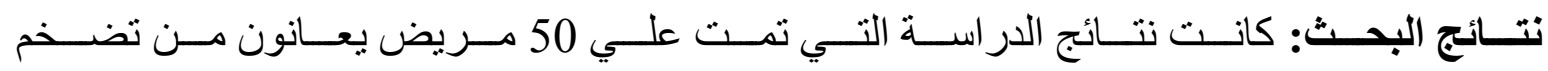

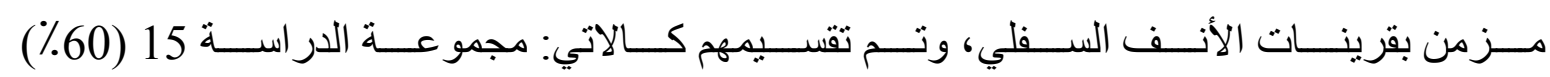

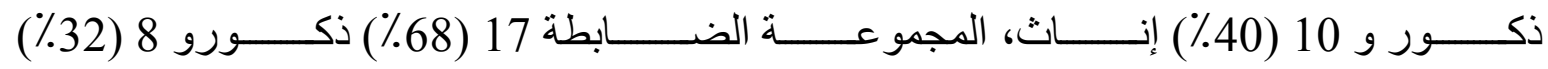

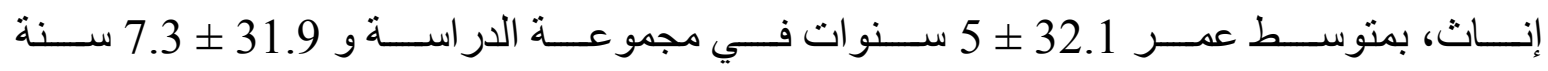

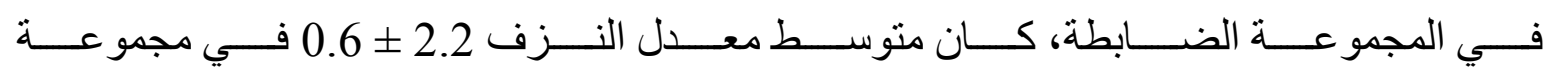

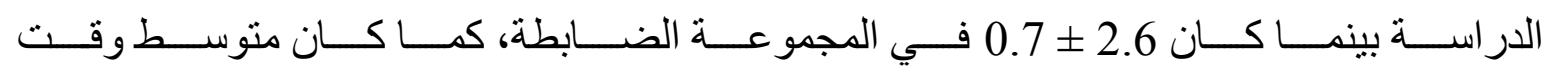

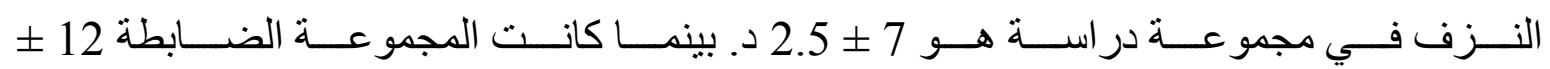

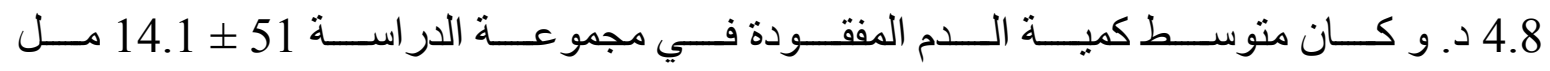
بينما كان 75 ( 14.2 مل في مجمو عة الضابطة.

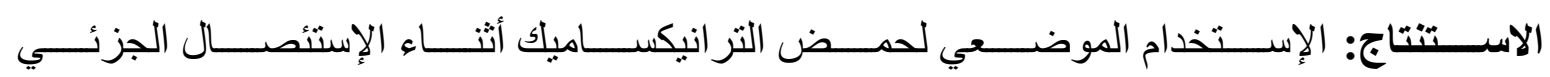

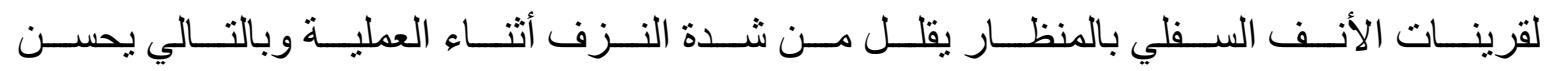
المجال الجر احي ويستغرق وقنتًا أقل. 